Article

\title{
Using the Direct Search Method for Optimal Dispatch of Distributed Generation in a Medium-Voltage Microgrid
}

\author{
Wei-Tzer Huang *, Kai-Chao Yao and Chun-Ching Wu \\ Department of Industrial Education and Technology, National Changhua University of Education, \\ No. 2, Shida Road, Changhua 500, Taiwan; E-Mails: kcyao@cc.ncue.edu.tw (K.-C.Y.); \\ wugch001@yahoo.com.tw (C.-C.W.) \\ * Author to whom correspondence should be addressed; E-Mail: vichuang@cc.ncue.edu.tw; \\ Tel.: +886-4-723-2105 (ext. 7264); Fax: +886-4-721-1287.
}

External Editor: Josep M. Guerrero

Received: 15 September 2014; in revised form: 28 November 2014 / Accepted: 4 December 2014 / Published: 12 December 2014

\begin{abstract}
This paper proposes a simple and efficient approach for the optimal dispatch in a medium-voltage microgrid (MG) with various types of distributed generation (DG). The fuel costs generated by these DGs are determined using quadratic and linear functions dependent on the types of DGs. Instead of using the traditional Lagrange multiplier method for power system economic dispatch, the proposed direct search method (DSM) approach is able to handle several inequality constraints without introducing any multipliers and furthermore it can solve the non-derivative problems or the fuel cost functions being much more complicated. Accordingly, the DSM is proposed for determining the optimal dispatch of MGs with various types of DG to minimize generation costs under grid-tied and autonomous operations. Results demonstrate that the proposed DSM is a highly suitable and simple approach to determining the optimal dispatch in medium-voltage MGs with various types of DG.
\end{abstract}

Keywords: direct search method (DSM); microgrid (MG); distributed energy resources (DERs); distributed generation (DG); optimal dispatch 


\section{Introduction}

Global warming is attributed to the greenhouse effect caused by increasing greenhouse gases, particularly carbon dioxide. For sustainable human development, the emission of greenhouse gases must be diminished; instead of fossil energy, renewable energy should be developed. Electricity generation from large, fossil fuel-based thermal power plants should first be reduced. A suitable alternative is to gradually increase electricity generation from clean and renewable distributed generation (DG) technologies, which are interconnected with distribution systems. Such technologies reduce the emission of $\mathrm{CO}_{2}$ and other special gases, improve operating efficiency, and eliminate the need to expand the transmission systems of existing power systems. Because of these benefits, DG development has become a popular trend. It is expected that lots of distributed energy resources (DERs), such as DG and distributed storage (DS) systems will interconnected with traditional electrical power distribution systems in the near future. According to Chen [1], DERs with rated capacities between $1 \mathrm{MW}$ and $25 \mathrm{MW}$ are usually interconnected with the bus bar of the secondary side of HV/MV distribution transformers. DERs with rated capacities between $100 \mathrm{~kW}$ and $1 \mathrm{MW}$ are commonly interconnected with primary distribution systems, and DERs with rated capacities of less than $100 \mathrm{~kW}$ are commonly interconnected with secondary distribution systems. In the current work, we focused on the optimal dispatch in microgrids (MGs) with various types of DG, whose capacities are between $100 \mathrm{~kW}$ and 2 MW. The DG systems are interconnected with primary distribution systems. In distribution systems with DERs, sophisticated techniques are required for steady state and transient operating conditions. Given that the planning, operation, and control of existing systems are affected by DG penetration, only the optimal control and dispatch strategies for the DG systems improve the performance of power distribution systems. To consider DG penetration, IEEE Std 1547-2003 [2] and IEC 61400-21 [3] provide technical specifications and requirements for interconnections to ensure the security and stability of existing power systems. The DG penetration levels of existing systems improve yearly because of sufficiently mature technological development and research. A MG is the part of a distribution system that includes DERs and controllable/uncontrollable loads with a single point of common coupling (PCC) [4,5]. The MG can be operated in grid-tied and autonomous modes. The use of MGs is the new development trend in power systems; hence, investigating the structure of the system, related operating control technology, and scheduling management is necessary.

Optimal dispatch problems are one of the key factors that affect operation cost and keep constant voltage and frequency in MGs operation. Yu et al. [6] proposed the economic benefit model, which consists of reduction of peak shaving cost, generation benefit of DGs, reduction of the network loss and the benefit of energy storage systems, for the operation optimization of an active distribution network. Kim et al. [7] proposed a multi-agent system for autonomous operation of the islanded MG in a power market environment. Liu et al. [8] used an inexact mix-integer two-stage programming model for the management of low-carbon energy systems. Jin et al. [9] suggested some strategies for sustainable development of energy management systems (EMSs) in western China. Chen et al. [10] presented a smart EMS to optimize the operation of the MG. Mohamed et al. [11] used a mesh adaptive direct search method (DSM) for online optimal management of the MG. Chung et al. [12] presented power control methods which used the particle swarm optimization algorithm and gain-scheduling method, to coordinate multiple MG generators for both grid-connected 
and autonomous modes. Kuo et al. [13] designed multi-agent systems for real-time intelligent control in MGs. The related researches mentioned above have advantages and disadvantages on their proposed algorithms and approaches and have been verified in different cases and systems. The direct search algorithms use only function values and require only a numerical value without any knowledge of the internal structure of a problem. The first time that the phrase "direct search" was used in a paper was by Hooke and Jeeves in 1961 [14]. DSM is easily adapted to nonlinear, non-convex, non-differentiable, or disconnected problems, making it highly suitable for solving the optimal dispatch problem in MGs with various DG types that are composed of different operation cost functions. Based on the optimization techniques mentioned above, this paper proposes a simple and efficient DSM for solving optimal dispatch problem with five the types of DG into several existing primary distribution feeders to create a medium-voltage MG. We simulated the optimal dispatch of DG, considering the minimization of fuel costs under grid-tied and autonomous conditions. In the remainder of this paper, the proposed MG is discussed in Section 2. The optimal dispatch problem of the MG is described in Section 3. The numerical results are discussed in Section 4. Section 5 concludes the paper.

\section{Description of the Microgrid}

Optimal dispatch in MGs is intended for the effective and safe management of various DG systems and controllable loads. Given this purpose, we used a Taipower $11.4 \mathrm{kV}$ distribution system to plan and design a medium-voltage MG that is composed of two primary distribution feeders. The proposed DSM is used to solve the optimal dispatch problem under grid-tied and autonomous conditions. The detailed descriptions of the MG system structure and the related DG parameters are discussed in the succeeding subsections.

\subsection{Structure of the Medium-Voltage Microgrid}

Figure 1 shows a typical Taipower distribution system, which comprises a $25 \mathrm{MVA}, 69 \mathrm{kV} / 11.4 \mathrm{kV}$, $60 \mathrm{~Hz}$ distribution transformer and five primary distribution feeders. The $11.4 \mathrm{kV}$ medium-voltage $\mathrm{MG}$ is part of the distribution system. Feeders F\#1 and F\#2 can be regarded as a two-feeder MG (F\#1\&2 MG) with various DG types and lump-sum loads, or as two separate single-feeder MGs, F\#1 MG and F\#2 MG. The remaining feeders, F\#3-F\#5, are traditional feeders without DG, and can be considered having lump-sum loads.

F\#1 MG consists of the following DG units: two gas turbine generators, two $1790 \mathrm{~kW}$ fuel cell generation systems, and a $500 \mathrm{~kW}$ photovoltaic generation system. The equivalent lump-sum load types of F\#1 MG are residential, office, and commercial. F\#2 MG consists of the following DG units: two $1500 \mathrm{~kW}$ diesel engine generators and a $1500 \mathrm{~kW}$ wind turbine generator. The equivalent lump-sum load types of F\#2 MG are residential and industrial. The above-mentioned DG units are all interconnected with primary feeders by power electronic converters, inverters, and isolated power transformers. A static switch is installed in the PCC of the MGs for grid-tied and autonomous operating conditions. 
Figure 1. System structure of an $11.4 \mathrm{kV}$ medium-voltage microgrid (MG).

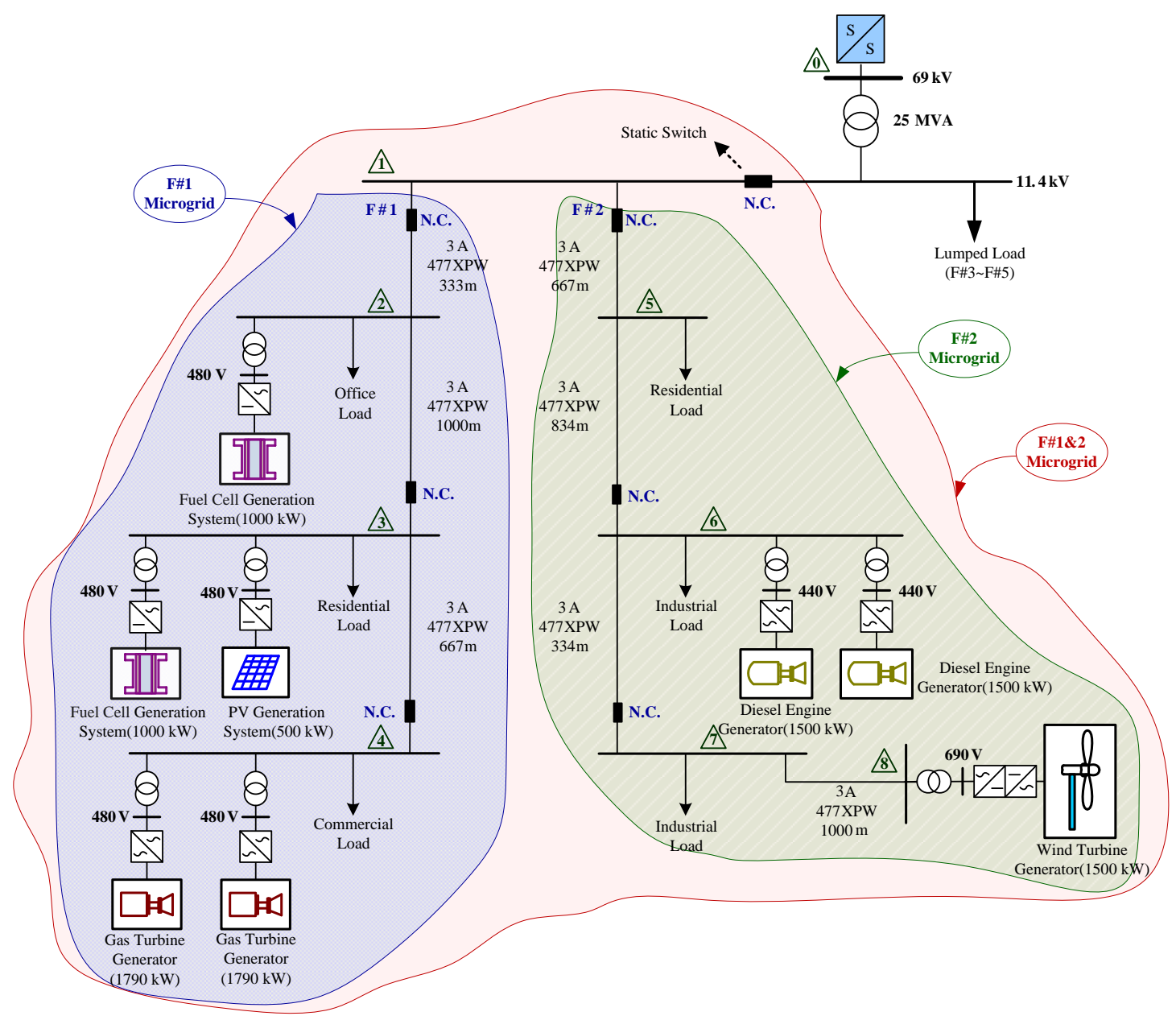

\subsection{Operation Conditions}

The operating conditions of MGs are as follows: (1) steady-state grid-tied operation; (2) steady-state autonomous operation under planned and unexpected situations; (3) transient operation from grid-tied to autonomous conditions; and (4) transient operation from autonomous to grid-tied conditions. In optimal dispatch problem, only steady-state grid-tied and autonomous operating conditions were considered. According to system structure, the available power output of DG units, and associated load demands, the proposed DSM was used to solve the optimal dispatch problem of DG in the MG under the aforementioned operating conditions. This work is similar to those on the economic dispatch or unit commitment in traditional power systems that consider coordination between available power and renewable energy units.

\subsubsection{Grid-Tied Operation}

Through a static switch, the F\#1\&2 MG is interconnected with the upper power grid in the PCC as shown in Figure 1. Under the grid-tied mode, the static switch is normally closed. Based on the minimization of fuel costs and power balance principle, the load demand in an MG is supplied by DG units and the purchased power from an upper power grid. Moreover, if the power supplied from DG units is greater than the load demand, the power will reverse to upper power grid through the PCC. 


\subsubsection{Autonomous Operation}

Through a static switch, the F\#1\&2 MG is disconnected from the upper power grid in the PCC. This operating condition can be divided into two sub-modes, depending on whether the available power output of the DGs is adequate for the load demand:

(1) When the available power output of DGs is greater than the load demand, dispatching renewable energy DG without fuel consumption and emissions is a top priority. However, if load demand is unsatisfied, non-renewable energy DG units must be used in the dispatch process and the reduction of fuel costs should be considered.

(2) When the available power output of DG units is less than the load demand, All the DG units in the MG should be operated and the load shedding strategy should be used to stabilize system operation.

\subsection{Energy Management System}

The EMS is the core of the medium-voltage MG, in which in low-voltage mg, it is called the low-voltage MG control center (LVMGCC). The EMS must coordinate and integrate the upper power grid, all the DG units, and loads into the MG to optimize dispatching electrical power among them and to keep system voltage and frequency constant under all operating conditions. Consequently, the primary goal is to fully grasp the real-time system states; thus, the EMS must be immigrated to the traditional distribution automation system and the correlative operating control center. The hierarchical dispatch and control system (HDCS) in Taipower (Taipei, Taiwan) for power dispatching among each distinct area, as shown in Figure 2; furthermore, this system is composed of three layers: (1) central dispatch and control center (CDCC); (2) area dispatch and control center (ADCC); and (3) distribution dispatch and control center (DDCC). The mentioned three-hierarchy architecture are responsible to the corresponding $345 \mathrm{kV}$ transmission systems, the $161 / 69 \mathrm{kV}$ buck power substations, and the 22.8/11.4 kV distribution substations, respectively. Besides, the feeder dispatch control center (FDCC) is located under the DDCC. Therefore, the EMS have to communicate interactively between the FDCC and MG in order to get the correlative information for real-time dispatch, as shown in Figure 2.

Figure 3 shows the functions of EMS of the MG, the functions of this system must not only grasp all the information of the upper power grid but also the DGs and loads in the MGs, and finally to fastly make the optimal operation and control decisions. The functions mentioned in Figure 3 for intelligent operation, control and, dispatch of the EMS must be implemented by correlative software and hardware; especially, the advanced and sophisticated information \& communication technologies (ICT) played an vital important role. Under this system structure, the EMS executes supervisory control and data acquisition of the remote DG units, loads, and upper power grid through the local controller via the ICT infrastructure. Moreover, in order to achieve the seamless integration of MG into the traditional power systems for the optimal operation and dispatch, the EMS must real-time bidirectional exchange the information between the MG and FDCC through the HDCS, as shown in Figure 2. 
Figure 2. Hierarchical dispatch and control system (HDCS). CDCC: central dispatch and control center; ADCC: area dispatch and control center; DDCC: distribution dispatch and control center; FDCC: feeder dispatch control center; EMS: energy management system; LVMGCC: low-voltage microgrid control center; and DG: distributed generation.

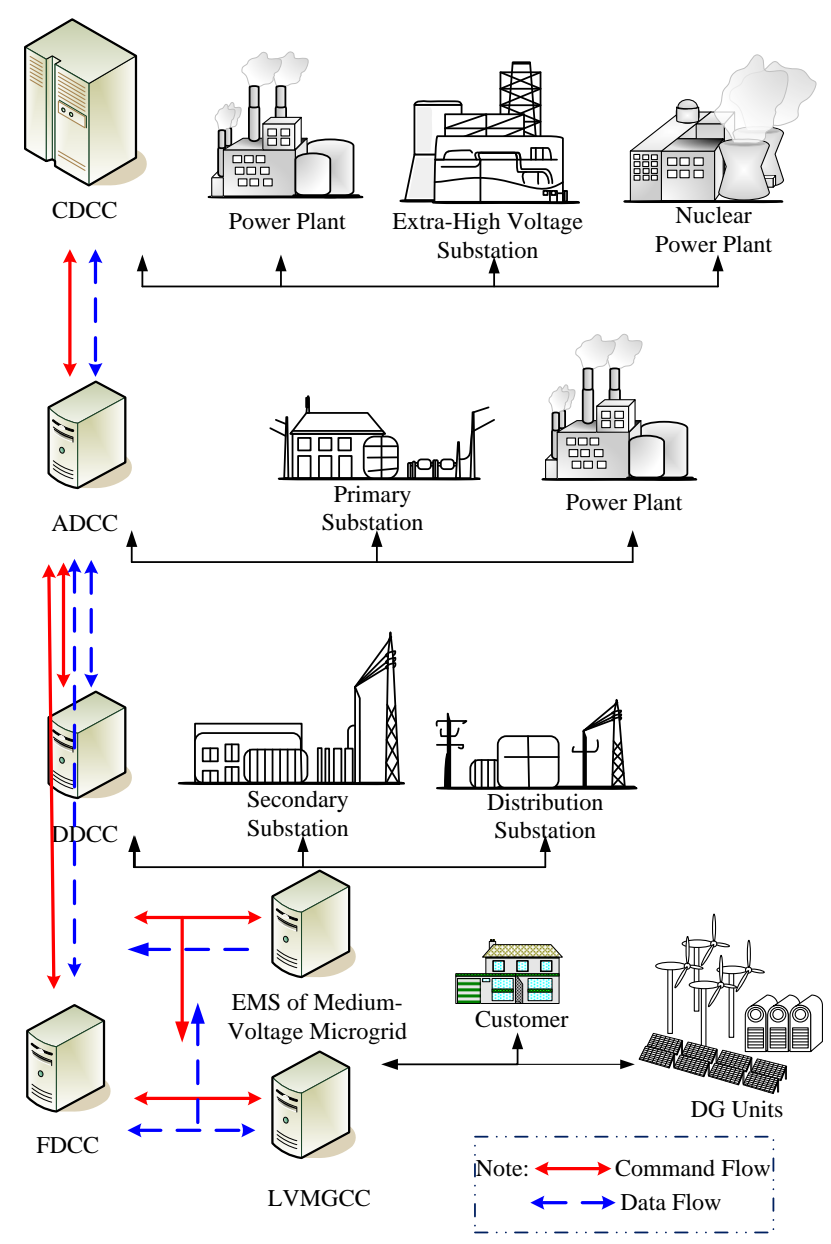

Figure 3. Functions of EMS. PCC: point of common coupling.

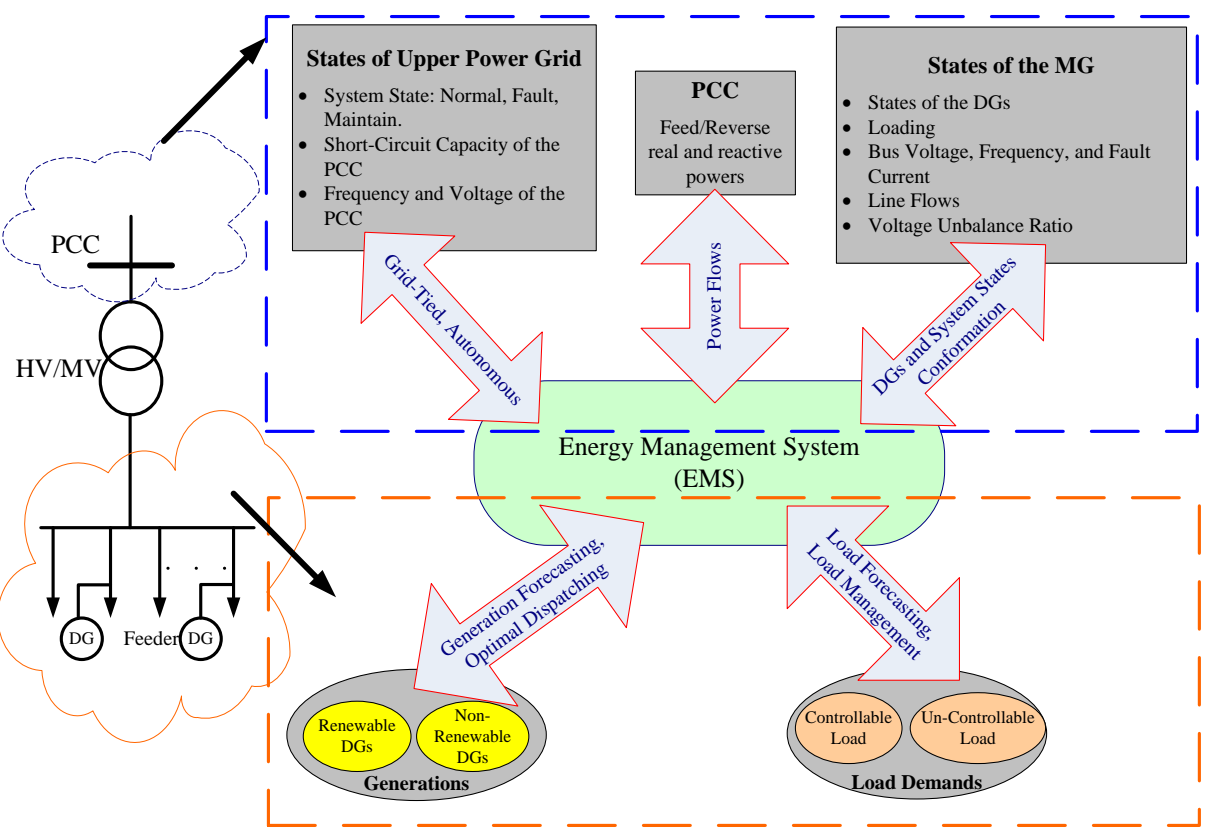




\subsection{Parameters of the Distributed Generations}

The operating considerations of the MG are distinct under varied operation modes. However, the best strategies for system operation are economical and reliable approaches, as well as those that present low emissions. The optimal dispatch problem of DG units in MGs is minimizing generation cost and reducing environmental pollution. The generation costs of an MG include fuel and emission costs, operation cost, maintenance cost, and purchasing or selling cost. To accurately calculate the generation cost of the MG in this paper, we considered the available power output of renewable energy DG units and fuel cost of non-renewable energy DG units.

\subsubsection{Available Power Output of Renewable Energy Distributed Generations}

\subsubsection{Wind Turbine Generator}

The available power output of a wind turbine generator is a function of wind speed. Equation (1) shows the model used to calculate the output power generated by the wind turbine generator $[15,16]$ :

$$
\left\{\begin{array}{lc}
P_{\mathrm{wt}}=0, & V<V_{\mathrm{ci}} \\
P_{\mathrm{wt}}=a \cdot V^{3}+b \cdot V^{2}+c \cdot V+d, & V_{\mathrm{ci}} \leq V<V_{\mathrm{r}} \\
P_{\mathrm{wt}}=P_{\mathrm{wt}, \mathrm{r}} & V_{\mathrm{r}} \leq V<V_{\mathrm{co}} \\
P_{\mathrm{wt}}=0, & V \geq V_{\text {co }}
\end{array}\right.
$$

where $P_{\mathrm{wt}, \mathrm{r}}$ is the rated power. $V, V_{\mathrm{r}}, V_{\mathrm{ci}}$, and $V_{\mathrm{co}}$ are the actual, rated, cut-in, and cut-out wind speeds, respectively. A GE-1.5xle wind turbine generator was used. The parameters in the model are as follows: $a=-2.608, b=63.201, c=293.3, d=374.23, P_{\mathrm{wt}, \mathrm{r}}=1500 \mathrm{~kW}, V_{\mathrm{ci}}=3.5 \mathrm{~m} / \mathrm{s}, V_{\mathrm{r}}=20 \mathrm{~m} / \mathrm{s}$, and $V_{\text {co }}=12.5 \mathrm{~m} / \mathrm{s}$ [17]. Using Equation (1) and the measured wind speed curve in Figure 4, we can obtain the power output curve of the GE-1.5xle wind turbine generator.

Figure 4. Measured wind speed curve.

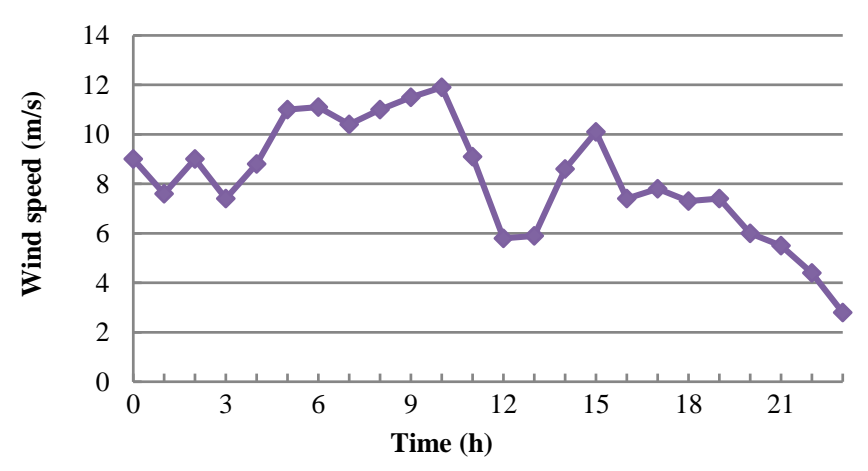

\subsubsection{Photovoltaic Generation System}

The power output of the photovoltaic module can be calculated using Equation (2) with the measured solar irradiation $\left(\mathrm{W} / \mathrm{m}^{2}\right)$ and ambient temperature $\left({ }^{\circ} \mathrm{C}\right)[18,19]$ :

$$
P_{\mathrm{pv}}=P_{\mathrm{stc}} \frac{G_{\mathrm{ing}}}{G_{\mathrm{stc}}}\left[1+k\left(T_{\mathrm{c}}-T_{\mathrm{r}}\right)\right]
$$


where $P_{\mathrm{pv}}$ is the output power of the module at irradiance $G_{\mathrm{ing}} ; P_{\mathrm{stc}}$ denotes the maximum power at the standard test condition; $G_{\text {ing }}$ is the incident irradiance; $G_{\text {stc }}$ represents the irradiance at the standard test condition $\left(1000 \mathrm{~W} / \mathrm{m}^{2}\right) ; k$ is the temperature coefficient of power; $T_{\mathrm{c}}$ denotes the cell temperature; and $T_{\mathrm{r}}$ is the reference temperature. A Kyocera-2P $210 \mathrm{Wp}$ Photovoltaic Module (Kyocera, Taipei, Taiwan) was used. According to Equation (2), the solar irradiation and ambient temperature were measured as in Figure 5. The power output curve of the photovoltaic generation system was also obtained.

Figure 5. Measured solar irradiation curve.

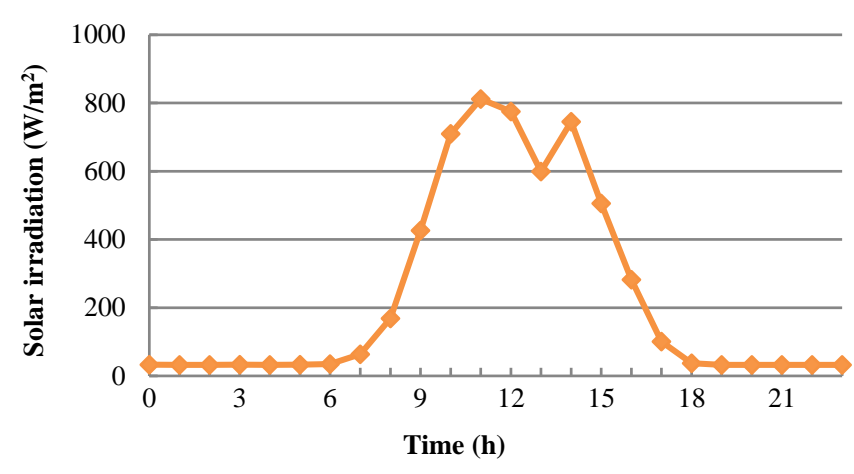

\subsubsection{Fuel Costs of Non-Renewable Energy Distributed Generation}

\subsubsection{Diesel Engine Generator}

The fuel cost of the diesel engine generator can be expressed as a quadratic polynomial function of its real power output, as shown in Equation (3) [20]:

$$
C_{\mathrm{DE}}=\alpha+\beta \cdot P_{\mathrm{DE}}+\gamma \cdot P_{\mathrm{DE}}^{2}
$$

where $\alpha, \beta$, and $\gamma$ are the generator coefficients that can be obtained from the data sheet of the manufacturer. $P_{\mathrm{DE}}$ is the power output of the diesel engine generator in $\mathrm{kW}$, and is assumed to be known.

\subsubsection{Fuel Cell Generation System}

Four major types of commercialized operating fuel cells currently exist: molten carbonate fuel cell (MCFC), solid oxide fuel cell (SOFC), proton exchange membrane fuel cell (PEMFC), and phosphoric acid fuel cell (PAFC). The fuel input of MCFC and SOFC is natural gas, and their rated capacities are relatively larger than that of PEMFC. Therefore, the MCFC and SOFC are more suitable for medium-voltage MGs. These two types of fuel cells were used in this study. The fuel cost of the fuel cell generator system is shown in Equation (4) [21]:

$$
C_{\mathrm{FC}}=C_{\mathrm{nl}} \sum_{J} \frac{P_{J}}{\eta_{J}}
$$

where $C_{\mathrm{nl}}$ is the natural gas price, $P_{J}$ denotes the net electrical power generated at interval $J$, and $\eta_{J}$ represents the fuel cell efficiency at interval $J$. 


\subsubsection{Gas Turbine Generator}

Similar to the fuel cost of the diesel engine generator, the gas turbine generator can be expressed as a quadratic polynomial function of its real power output:

$$
C_{\mathrm{GT}}=\alpha+\beta \cdot P_{\mathrm{GT}}+\gamma \cdot P_{\mathrm{GT}}^{2}
$$

\section{Description of the Optimal Dispatch Problem}

Many algorithms and techniques, such as mesh adaptive direct search, sequential quadratic programming, genetic algorithms, and game theory, have been used to solve the optimal dispatch problems of power systems. In general, the search algorithm can be divided into direct and indirect search algorithms, where the direct search algorithm only considers objective function, it is also called non-gradient or zeroth order method; however, the indirect search algorithm must consider partial derivatives of objective function, it is also called decent method. Furthermore, some of the direct search algorithms for solving nonlinear optimization are random search method, grid search method, pattern method, Rosen Brock's method, and simplex method, etc. References [11,22] had demonstrated the feasibility of direct search algorithm. This paper proposes the DSM, which is based on the simplex method to solve the optimal dispatch problem of a medium-voltage MG. The concept of the proposed DSM is according to the unit with minimum incremental cost $\left(I C_{\min }\right)$ is chosen to increase its output without violating the upper and lower power generation limits, until the power balance. On the contrary, the maximum incremental cost $\left(I C_{\max }\right)$ is chosen to decrease its output, until the power balance. It can be expressed as:

$$
I C_{i}=\frac{C_{i}\left(P_{i}+\Delta P_{i}\right)-C_{i}\left(P_{i}\right)}{\Delta P_{i}} \quad \text { for } i=1, \ldots, N
$$

subject to:

$$
P_{i}+\Delta P_{i} \leq P_{i, \max } \text { and } P_{i}-\Delta P_{i} \leq P_{i, \min }
$$

where $I C_{i}$ is the incremental cost of unit $i ; \Delta P_{i}$ denotes the predetermined computing step. Let $\Delta P_{i}$ approaches zero in Equation (7), Equation (7) can be represented as:

$$
I C_{i}=\lim _{\Delta P_{i} \rightarrow 0} \frac{C_{i}\left(P_{i}+\Delta P_{i}\right)-C_{i}\left(P_{i}\right)}{\Delta P_{i}}=\frac{\mathrm{d} C_{i}}{\mathrm{~d} P_{i}} \quad \text { for } i=1, \ldots, N
$$

It is easy to explain the incremental cost with respect to power changes in Equation (8). In this paper, a simplex method that chooses the minimum $I C$ values to compute the new vertices and moves towards the optimum point iteratively is used to perform the DSM. Furthermore, the basic principle of the proposed algorithm comes from the combinations of the conventional Lagrangian Relaxation method and dynamic programming method. Therefore, the proposed method has no restrictions on the cost functions of DG, which included distributed generators and power purchased/sold from power grid in MG, and performs a direct search of solution space. This algorithm begins with an initial feasible solution and search for the optimal solution along a feasible path at all time. Units in MG without violating the upper or lower limits are to increase or decrease their generations by a predetermined step $\Delta P$ for computing their incremental cost and decrement cost. Consequently, it overcomes the 
lambda-iteration method suffering from the oscillatory problem in various generation unit systems. Besides, the advantage of DSM is to handle several inequality constrains without introducing any multipliers, and it also can solve the derivatives unavailable problems or more complicated cost functions.

In this paper, the power output limits of the DG units of the medium-voltage MG can be derived after studying the power output models of renewable DG, the cost functions of non-renewable DG, the objective function that considers fuel cost minimization, and the constraints of power balance.

The objective function for the optimal dispatch problem at time $t$ can be expressed as follows:

$$
\text { Minimize } C_{\mathrm{T}}(t)=\sum_{i=1}^{N} C_{i}(t)\left(P_{\mathrm{DG}_{i}}(t)\right)+C_{\text {Purchased }}(t)\left(P_{\text {Purchased }}(t)\right)-C_{\text {Sold }}(t)\left(P_{\text {Sold }}(t)\right)
$$

subject to:

$$
\sum_{i=1}^{N} P_{\mathrm{DG}_{i}}(t)+P_{\text {Purchased }}(t)+P_{\mathrm{wt}}(t)+P_{\mathrm{pv}}(t)-P_{\mathrm{D}}(t)-P_{\text {loss }}(t)-P_{\text {Sold }}(t)=0
$$

and:

$$
\begin{gathered}
P_{\mathrm{DG}_{i}, \text { min }} \leq P_{\mathrm{DG}_{i}}(t) \leq P_{\mathrm{DG}_{i}, \text { max }} \quad \text { for } i=1, \ldots, N \\
V_{i, \text { min }} \leq V_{i}(t) \leq V_{i, \text { max }} \quad \text { for } i=1, \ldots, N \\
I_{i}(t) \leq I_{i, \text { max }} \quad \text { for } i=1, \ldots, N
\end{gathered}
$$

where $C_{i}(t)$ is the cost function of $i$-th DGs at time $t ; P_{\mathrm{DG}_{i}}(t)$ denotes the power generation of $i$-th DGs at time $t$; and $P_{\mathrm{D}}(t)$ represents the total load demand of the MG at time $t$. Additionally, $C$ Purchased $(t)$ is the electricity purchased cost at time $t ; C \operatorname{Sold}(t)$ is the electricity sold cost at time $t ; P$ Purchased $(t)$ represents the power purchased from the upper utility power grid; $P_{\text {loss }}(t)$ represents the system power loss; and $P_{\text {Sold }}(t)$ represents the power sold to the utility power grid. Besides, $P_{\mathrm{DG}_{i}, \text { min }}$ is the lower generation limit of $i$-th DGs; $P_{\mathrm{DG}_{i}, \max }$ represents the upper generation limit of $i$-th DGs; $V_{i, \min }$ and $V_{i, \max }$ are the lower and upper limits of bus voltage, respectively. The setting values of $V_{i \text {,min }}$ and $V_{i, \max }$ are 0.975 p.u. and 1.025 p.u. In addition to, $I_{i, \max }$ represents the maximum ampere capacity of the conductor, and the maximum normal operating current of the 477 cross-linked polyethylene wire (XPW) conductor is 300 A in Taipower.

In this paper, the implicit $Z_{\mathrm{BUS}}$ Gauss method [23] was used for solving the three-phase power flow. The implicit $Z_{\text {BUs }}$ Gauss method is based on the principle of superposition applied to the bus voltages along the feeders. The voltage on each bus can be considered to be contributed from two different types of sources: the specified incoming bus voltage of distribution substation and current injection which is generated by the DGs, loads, capacitors and reactors. After running the power flow program, the bus voltage, current flows in each line section, and power loss were calculated. These numerical values were used to exam the constraints of the proposed approach. The specific parameters of the MG for solving power flow are listed in Table 1. 
Table 1. Parameters of the circuit components. PV: photovoltaic; and XPW: cross-linked polyethylene wire.

\begin{tabular}{ccc}
\hline Components & Parameter & Value \\
\hline Equivalent source of the power grid & Short-circuit capacity & $8129 \mathrm{MVA}$ \\
& X/R & 34 \\
\hline Main transformer (delta-grounded Y connection) & Rated capacity & $25 \mathrm{MVA}$ \\
& Per-unit impedance, X/R & $8 \%, 16.32$ \\
\hline Interconnected transformer & Rated voltage & $161 \mathrm{kV} / 11.4 \mathrm{kV}$ \\
\hline (grounded Y-grounded Y connection) of fuel cell & Rated capacity & $1500 \mathrm{kVA}$ \\
generation system and wind turbine generator & Per-unit impedance, X/R & $6 \%, 7$ \\
\hline Interconnected transformer & Rated voltage & $11.4 \mathrm{kV} / 0.48 \mathrm{kV}$ \\
(grounded Y-grounded Y connection) of gas turbine & Rated capacity & $2000 \mathrm{kVA}$ \\
and diesel engine generators & Per-unit impedance, X/R & $4.9 \%, 10$ \\
\hline Interconnected transformer & Rated voltage & $11.4 \mathrm{kV} / 0.48 \mathrm{kV}$ \\
\hline (grounded Y-grounded Y connection) of & Rated capacity & $500 \mathrm{kVA}$ \\
PV generation system & Per-unit impedance, X/R & $9.6 \%, 7$ \\
\hline Primary feeder (477 XPW) & Rated voltage & $11.4 \mathrm{kV} / 0.48 \mathrm{kV}$ \\
\hline
\end{tabular}

The following steps can organize the procedure of the proposed DSM:

Step 1 Input data: system topology, load demand, maximum demand contract, purchased/sold electricity cost, cost function of DGs, and generation limits of DGs.

Step 2 Set up the computation step $\Delta P$, and compute the initial values of the $I C$ for each DG using Equations (4), (6) and (8).

Step 3 Read the power demand $P_{\mathrm{D}}$, and calculate the summation of minimum output for each DG and minimum purchased electricity from upstream power grid (only under grid-tied operation conditions), and run the power flow program to check the constraints, then calculate the mismatch of power balance ( $\varepsilon$ ) using Equation (10), if it is power balance, then stop the iteration procedure, and go to Step 7.

Step 4 If $\varepsilon$ is negative, it means the power demand is greater than the power output, so the DG without violating the upper limits is chosen to increase its output by computation step $\Delta P$ (the upstream power grid is included in grid-tied mode). Compute new value of $I C$ for the dispatched DG, and run power flow program to check the constraints and calculate $\varepsilon$, if it is power balance, then it is convergence, and go to Step 7.

Step 5 If $\varepsilon$ is positive, it means the power demand is less than power output, the DG without violating the lower limits is chosen to decrease its output by computation step $\Delta P$ (the upstream power grid is included in grid-tied mode). Restore the previous value of $I C$ for the dispatched DG, and run power flow program to check the constraints and calculate $\varepsilon$, if it is power balance, then it is convergence, and go to Step 7.

Step 6 Calculate the output of each DG and the total cost $C_{\mathrm{T}}$ using Equation (9).

Step 7 Stop calculations and output hourly optimal dispatch results. 
As stated above, the flow chart of the proposed DSM for hourly dispatch can be illustrated in Figure 6. In this paper, it is an hourly dispatch problem, but the proposed approach is not limit to hourly dispatch problem, in which it is dependent on the input data, such as the generations of renewable units and load demands.

Figure 6. Flow chart of the proposed direct search method (DSM).

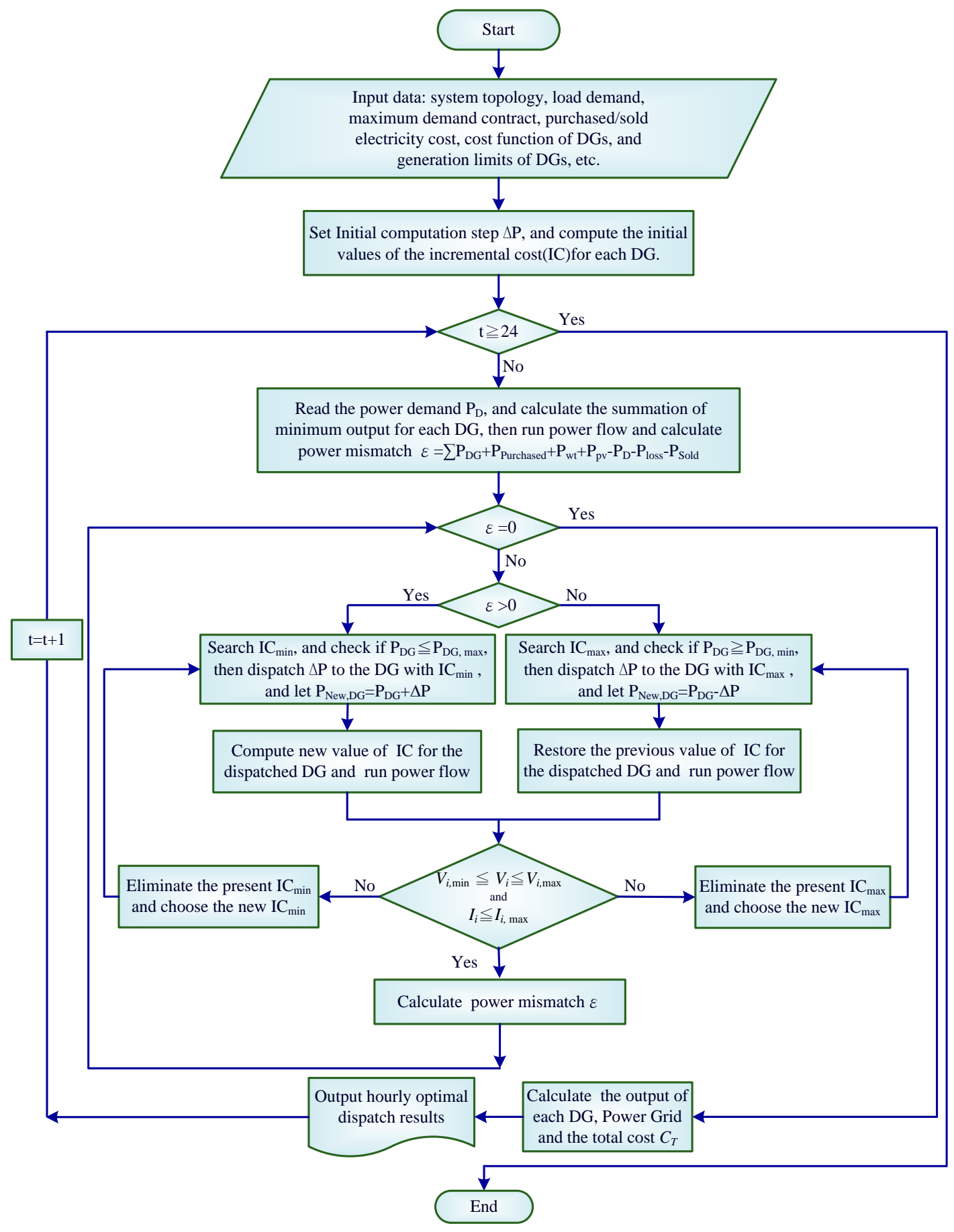

In using the DSM in solving the optimal dispatch problem of a medium-voltage MG, the F\#1\&2 MG (Figure 1) is chosen as the sample system. The correlative detailed data are first incorporated; this data include correct weather forecasting, load data, and generation data. The parameters of each DG are listed in Table 2. 
Table 2. Parameters of the DGs.

\begin{tabular}{|c|c|c|c|c|}
\hline \multirow{2}{*}{ Parameters } & \multirow{2}{*}{$\begin{array}{c}\text { Rated capacity } \\
(\mathbf{k W})\end{array}$} & \multicolumn{3}{|c|}{ Generating cost of coefficient } \\
\hline & & $\alpha(\$ / h)$ & $\boldsymbol{\beta}(\mathbf{S} / \mathbf{k W} \cdot \mathbf{h})$ & $\gamma\left((\$ / k W \cdot h)^{2}\right)$ \\
\hline Fuel cell generation system (FC\#1, FC\#2) & 1000 & 0 & 0.0848 & 0 \\
\hline Diesel engine generator (DE\#1, DE\#2) & 1500 & 0.3312 & 0.0156 & 0.0002484 \\
\hline Gas turbine generator (GT\#1, GT\#2) & 1790 & 0.4969 & 0.0116 & 0.0001987 \\
\hline
\end{tabular}

The purchased/sold electricity cost of the F\#1\&2 MG are depicted in Figure 7. The purchased/sold electricity cost includes peak-load $(0.2392$ \$USD/kW·h), half-peak-load (0.0894 \$USD/kW·h), and off-peak-load $(0.0447 \$ \mathrm{USD} / \mathrm{kW} \cdot \mathrm{h})$ pricing from the upstream utility power grid during the summer season.

Figure 7. Electricity purchased/sold cost of the MG.

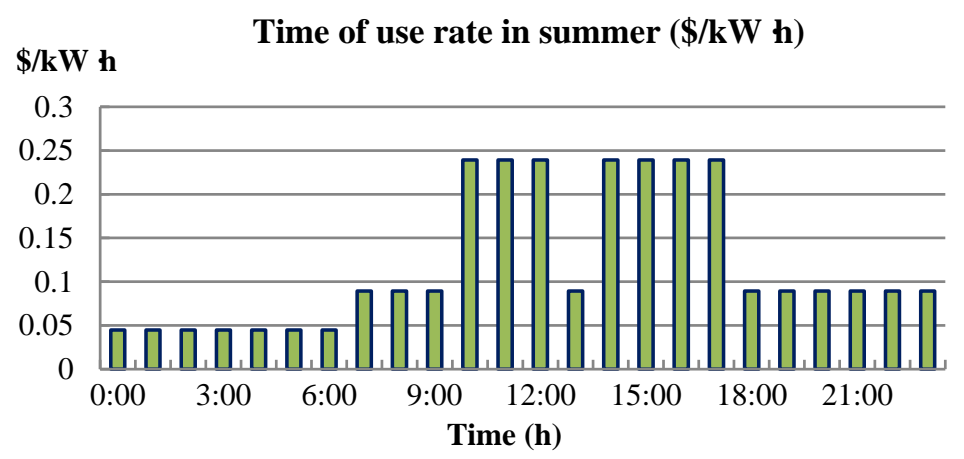

The equivalent lumped daily load demand curves for specific summer days, which correspond to different load types at each bus, are illustrated in Figure 8. The real power generation curves of renewable energy DG can be calculated using corresponding equations, measured solar irradiation, and wind speed data (Section 2.4.1). Computation step $\Delta P$, which affects iteration number, execution time, and results, is essential to the proposed DSM. We set $\Delta P$ to $1 \mathrm{~kW}$.

Figure 8. Equivalent lump-load demand curve at each bus: (a) real power; and (b) reactive power.

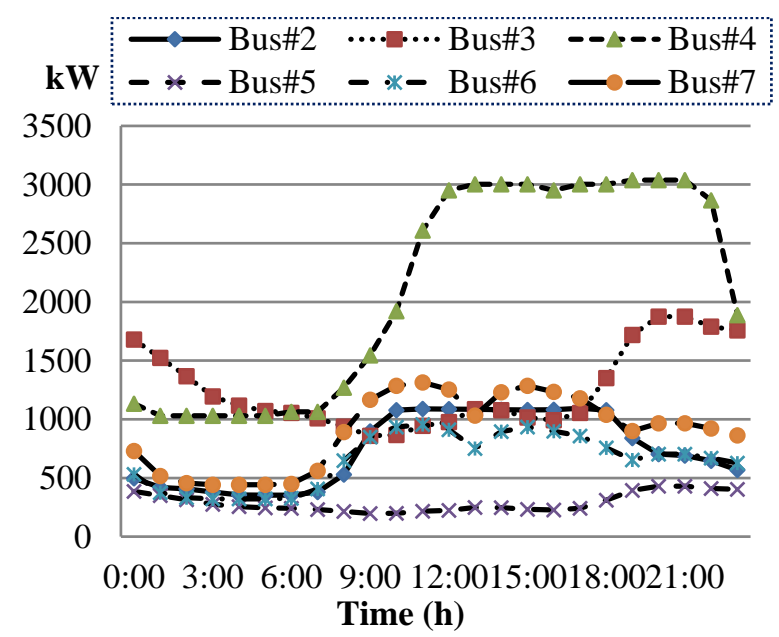

(a)

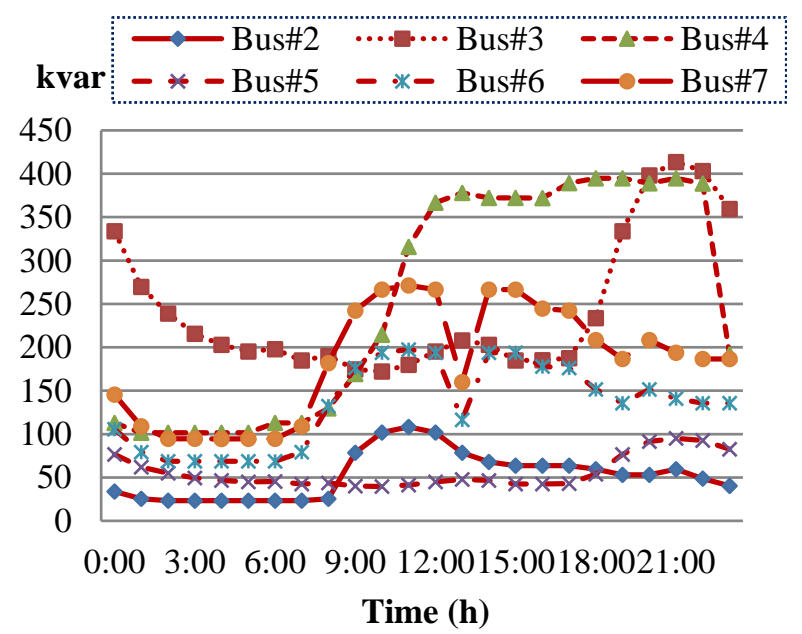

(b) 


\section{Numerical Results and Discussion}

To verify the effectiveness of the proposed DSM, it was first used to evaluate the traditional economic dispatch problem of the IEEE 14-Bus and 30-Bus test systems, and the cost coefficients of the generators in this test system are shown in Table 3.

Table 3. The generator cost coefficient of the IEEE 14-bus and 30-bus test systems.

\begin{tabular}{|c|c|c|c|c|c|c|c|c|c|}
\hline \multirow{2}{*}{ Cost coefficient } & \multicolumn{3}{|c|}{ IEEE 14-bus } & \multicolumn{6}{|c|}{ IEEE 30-bus } \\
\hline & Bus 1 & Bus 2 & Bus 6 & Bus 1 & Bus 2 & Bus 5 & Bus 8 & Bus11 & Bus13 \\
\hline$a_{i}$ & 105 & 245 & 50 & 40 & 45 & 40 & 50 & 60 & 45 \\
\hline$b_{i}$ & 44 & 351 & 50 & 340 & 350 & 330 & 360 & 350 & 340 \\
\hline$c_{i}$ & 40 & 389 & 50 & 40 & 50 & 45 & 40 & 45 & 45 \\
\hline
\end{tabular}

Note: the fuel cost of generator $i$ is represented as $C_{i}=a_{i}+b_{i} \cdot P_{i}+C_{i} \cdot P_{i}^{2}$.

The numerical results are listed in Table 4. In order to check the convergence condition, two predetermined resolution (e.g., $P_{\mathrm{D}}=0.1 \mathrm{MW}, P_{\mathrm{D}}=1 \mathrm{MW}$ ) are used to choose the fixed calculation step for every unit. The simulation results demonstrated that the $P_{\mathrm{D}}$ is sensitive to the performance of DSM. If the $P_{\mathrm{D}}$ is too large, then it may end up with divergence. On the contrary, the smaller $P_{\mathrm{D}}$ will result in more central processing unit (CPU) execution time. Based on our simulation experience, a proper predetermined resolution is about $1-10 \mathrm{MW}$ in transmission system level and is about $1-10 \mathrm{~kW}$ in distribution system level. Besides, the generation cost is not very sensitive to $P_{\mathrm{D}}$; in other words, the solutions are close to the optimal solution during the rough convergence level. In Table 4, the simulation results of the proposed approach are nearly the same as those derived using the Lagrange multiplier. Thus, the developed DMS program is valid. The optimal dispatch problem of the medium-voltage MG was then solved using the DSM program.

Table 4. Comparison of the simulation results of the Lagrange multiplier method and the DSM for the economic dispatch of the IEEE test systems. CPU: central processing unit.

\begin{tabular}{|c|c|c|c|c|c|}
\hline \multirow[b]{2}{*}{ Method } & \multicolumn{2}{|c|}{ IEEE 14-bus test system } & \multirow[b]{2}{*}{ Method } & \multicolumn{2}{|c|}{ IEEE 30-bus test system } \\
\hline & $\begin{array}{l}\text { Lagrange } \\
\text { multiplier }\end{array}$ & DSM & & $\begin{array}{l}\text { Lagrange } \\
\text { multiplier }\end{array}$ & DSM \\
\hline \multirow{2}{*}{ Bus 1} & \multirow{2}{*}{$134.2 \mathrm{MW}$} & \multirow{2}{*}{ 134.2 MW } & Bus 1 & $73.2 \mathrm{MW}$ & $73.2 \mathrm{MW}$ \\
\hline & & & Bus 2 & $58.5 \mathrm{MW}$ & $58.5 \mathrm{MW}$ \\
\hline \multirow{2}{*}{ Bus 2} & \multirow{2}{*}{ 133.1 MW } & \multirow{2}{*}{ 133.1 MW } & Bus 5 & $65.2 \mathrm{MW}$ & $65.2 \mathrm{MW}$ \\
\hline & & & Bus 8 & $73.0 \mathrm{MW}$ & $73.0 \mathrm{MW}$ \\
\hline \multirow{2}{*}{ Bus 6} & \multirow{2}{*}{ 132.7 MW } & \multirow{2}{*}{ 132.7 MW } & Bus 11 & $65.0 \mathrm{MW}$ & $65.0 \mathrm{MW}$ \\
\hline & & & Bus 13 & $65.1 \mathrm{MW}$ & $65.1 \mathrm{MW}$ \\
\hline Load demand & $400 \mathrm{MW}$ & $400 \mathrm{MW}$ & Load demand & $400 \mathrm{MW}$ & $400 \mathrm{MW}$ \\
\hline Total cost & $2,798.13 \$ / \mathrm{h}$ & $2,798.13 \$ / \mathrm{h}$ & Total cost & $1,309.06 \$ / \mathrm{h}$ & $1,309.06 \$ / \mathrm{h}$ \\
\hline $\begin{array}{l}\text { CPU execution } \\
\text { time (s) }\end{array}$ & 0.020 & $\begin{array}{l}0.010\left(@ P_{\mathrm{D}}=0.1 \mathrm{MW}\right) \\
0.009\left(@ P_{\mathrm{D}}=1.0 \mathrm{MW}\right)\end{array}$ & $\begin{array}{l}\text { CPU execution } \\
\text { time }(\mathrm{s})\end{array}$ & 0.060 & $\begin{array}{l}0.050\left(@ P_{\mathrm{D}}=0.1 \mathrm{MW}\right) \\
0.010\left(@ P_{\mathrm{D}}=1.0 \mathrm{MW}\right)\end{array}$ \\
\hline
\end{tabular}




\subsection{Optimal Dispatch under Grid-Tied Operation of the F\#1\&2 Microgrid}

On the basis of the daily load demand curve in Figure 8 and the maximum available power generation of the renewable energy DG, we show the numerical results of the optimal dispatch under the grid-tied operation of the F\#1\&2 MG in Figures 9-12, respectively. As shown in Figures 9 and 10, the numerical results demonstrate that the bus voltage and current flow do not violate the constraints.

Figure 9. Numerical results of bus voltage under grid-tied operation.

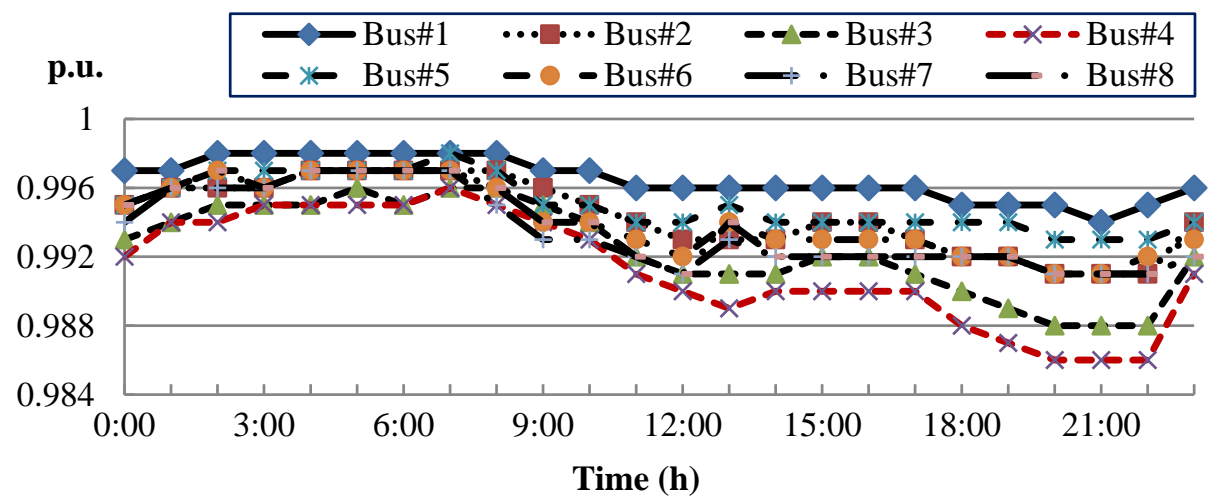

Figure 10. Numerical results of current flow under grid-tied operation.

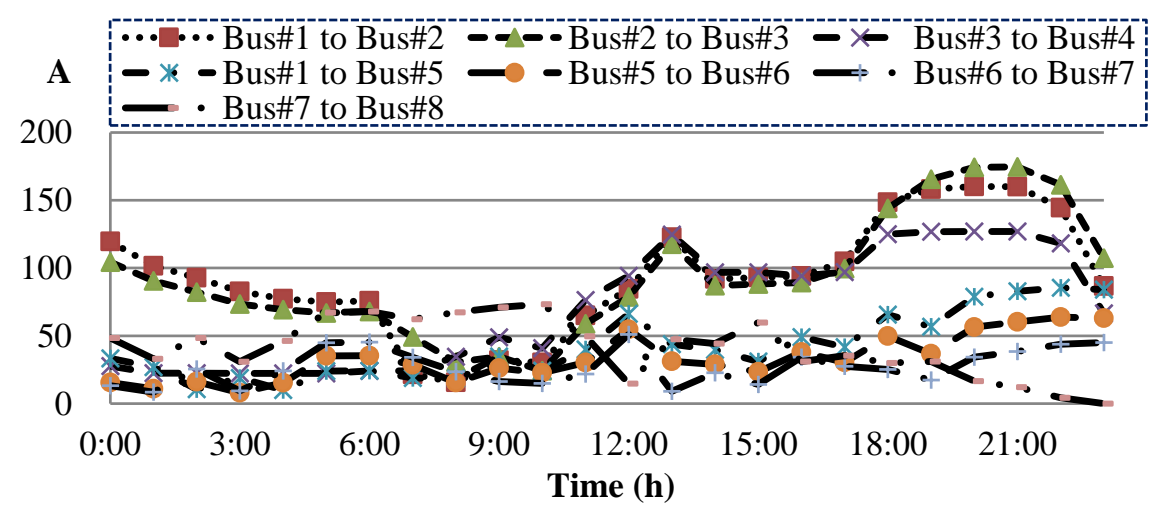

Figure 11 illustrates the optimal power generation of the utility power grid and DG units under various 24-h load demands.

Figure 11. Numerical results for the optimal generation of each DG and utility power grid under grid-tied operation.

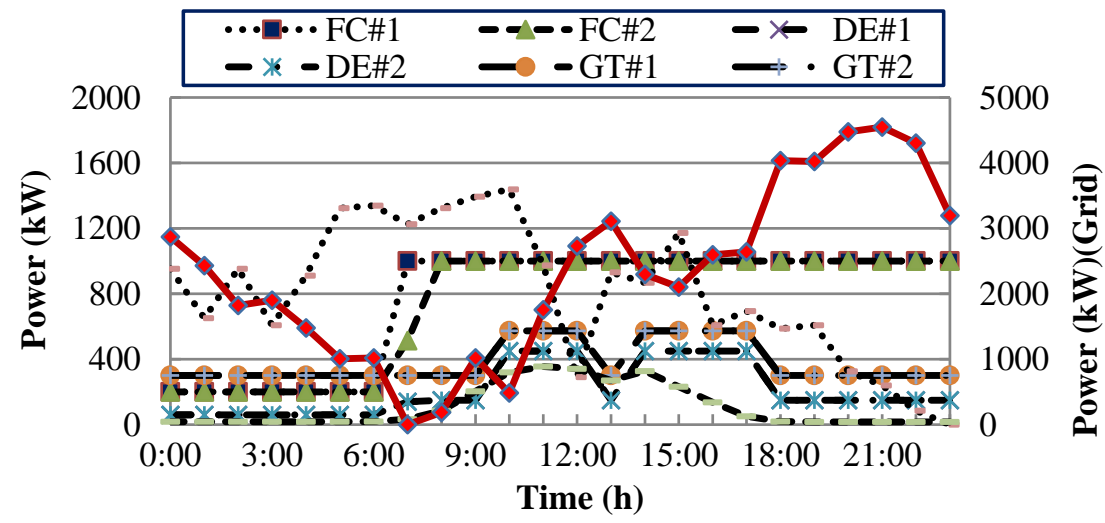


The power losses and total generation cost of the F\#1\&2 MG are shown in Figure 12. Overall, because the electricity purchase cost from the utility power grid pertains primarily to the duration of high-voltage use in summer, the equivalent electricity purchased cost per $\mathrm{kW} \cdot \mathrm{h}$ is relatively lower than that of non-renewable energy DG. Consequently, the power output from the utility power grid is greater than those from the other DG units, except the non-fuel cost, renewable energy units. Therefore, the power generation of each unit is inversely proportional to its corresponding incremental cost; that is, as the DG incremental cost decreases, the power generated by the DG increases. Moreover, the computing time of the proposed DSM at $P_{\mathrm{D}}$ equals $1 \mathrm{~kW}$ is about $0.42 \mathrm{~s}$.

Figure 12. Numerical results of (a) power losses and (b) total generation cost under grid-tied operation.

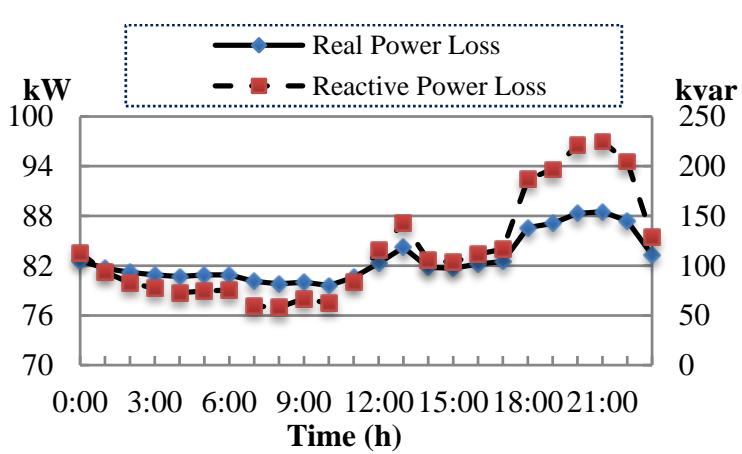

(a)

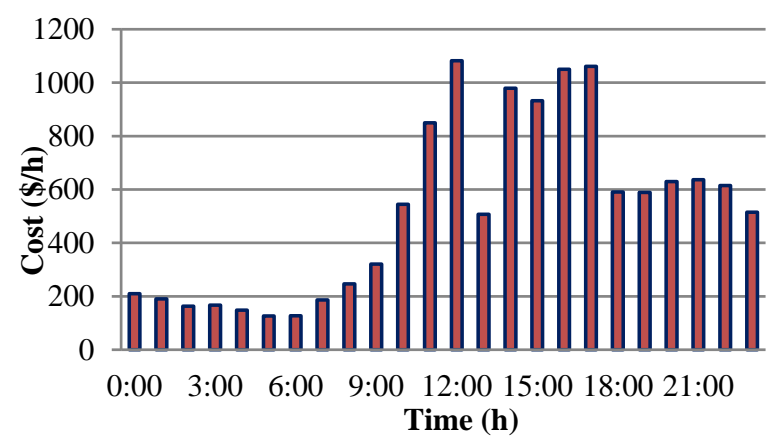

(b)

\subsection{Optimal Dispatch of the F\#1\&2 Microgrid under Autonomous Operation}

When a fault occurs in the upper power grid or during regular maintenance, the F\#1\&2 MG operates in autonomous mode after the static switch at the PCC is turned off. The numerical results for optimal dispatch are shown in Figures 13-16. Because no utility power grid acts as a swing bus under this operation mode, the available power output of the DG units must be greater than the power demand of the F\#1\&2 MG to ensure stable system operation. System frequency and voltage magnitude are then maintained in accordance with the power balance principle. Otherwise, an optimal load shedding strategy should be used to maintain power balance, an issue that we will address in future research. The available power output of the DG units is greater than the load demand. In this paper, the diesel engine generators act as swing bus in this study. As shown in Figures 13 and 14, the numerical results demonstrate that the bus voltage and current flow are not violate the constraints.

Figure 13. Numerical results of bus voltage under autonomous operation.

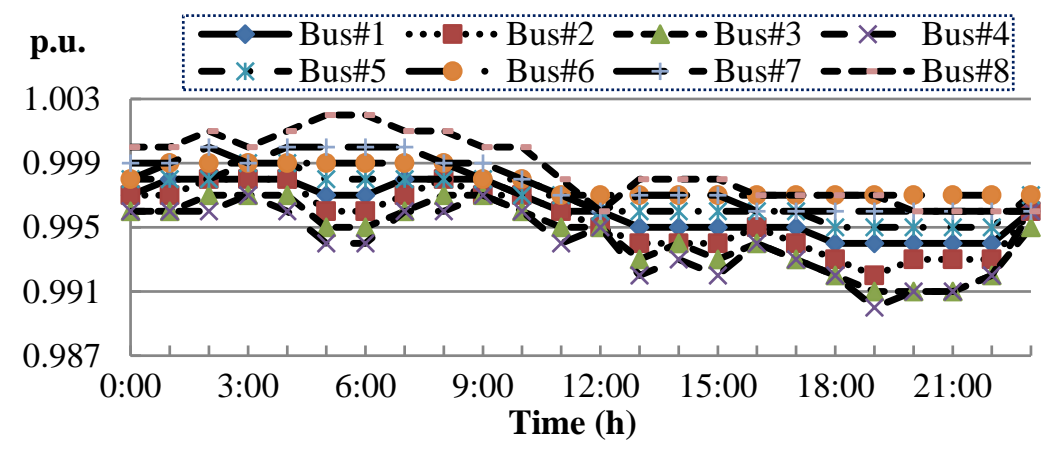


Figure 14. Numerical results of current flow under autonomous operation.

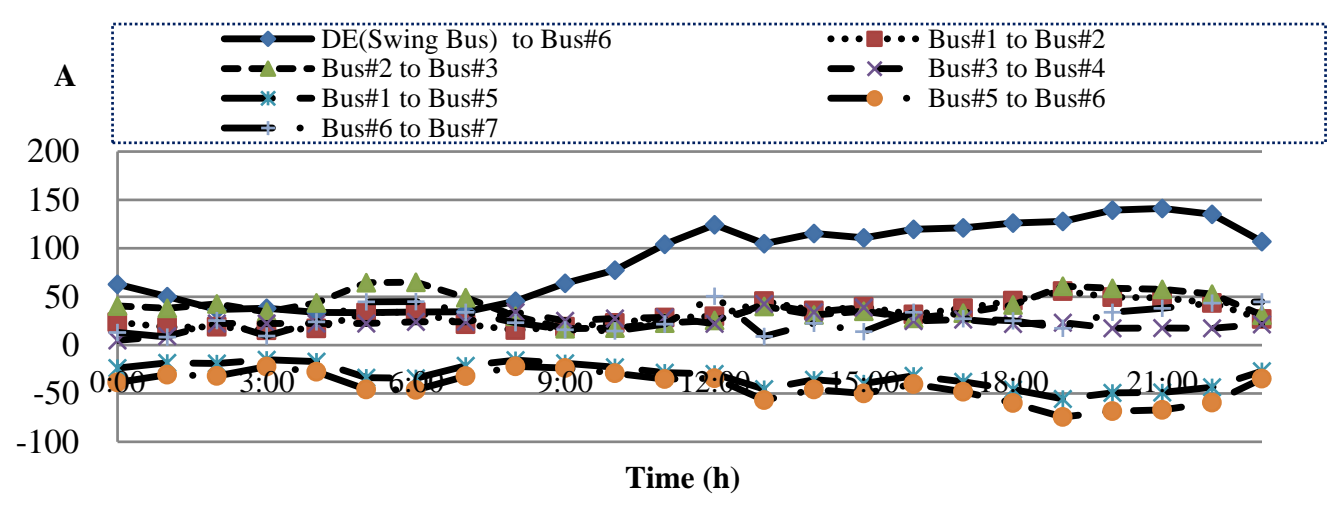

Figure 15 shows the optimal power generation of the DG units under various 24-h load demands.

Figure 15. Numerical results for the optimal generation of each DG under autonomous operation.

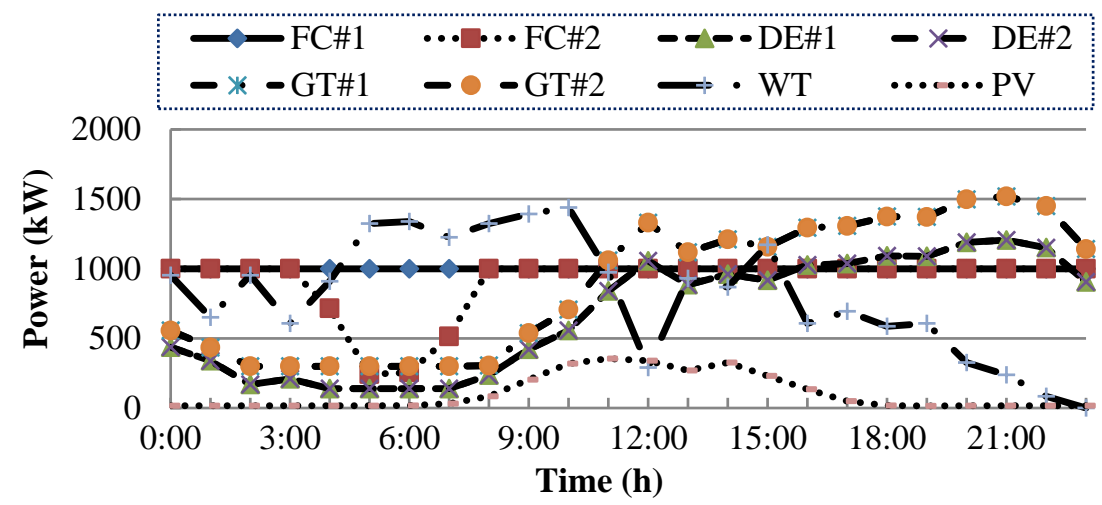

The power losses and total generation cost of the F\#1\&2 MG are shown in Figure 16. Under the same load demands, the average incremental cost and generation cost of the F\#1\&2 MG that operates in autonomous mode are considerably greater than those of the F\#1\&2 MG that operates in grid-tied mode. The simulation results are attributed primarily to the MG loss from the power generated by the utility power grid, whose generation cost is lower than that of the other DG units. Furthermore, the computing time of the proposed DSM at $P_{\mathrm{D}}$ equals $1 \mathrm{~kW}$ is about $0.40 \mathrm{~s}$.

Figure 16. Numerical results of (a) power losses and (b) total generation cost under autonomous operation.

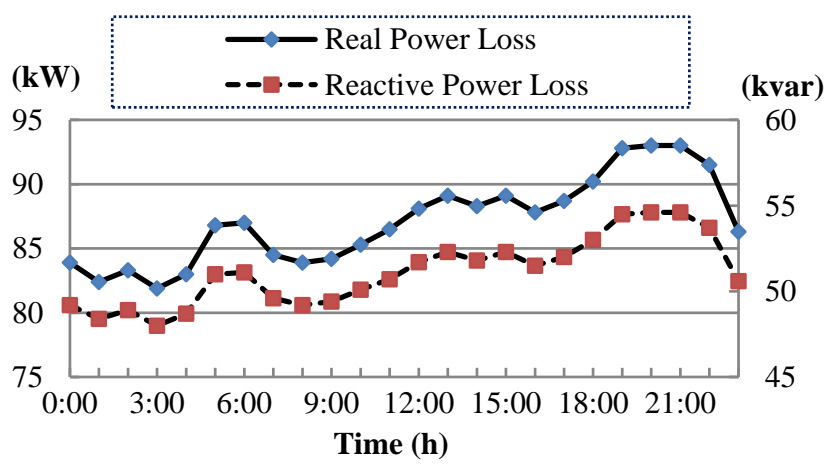

(a)

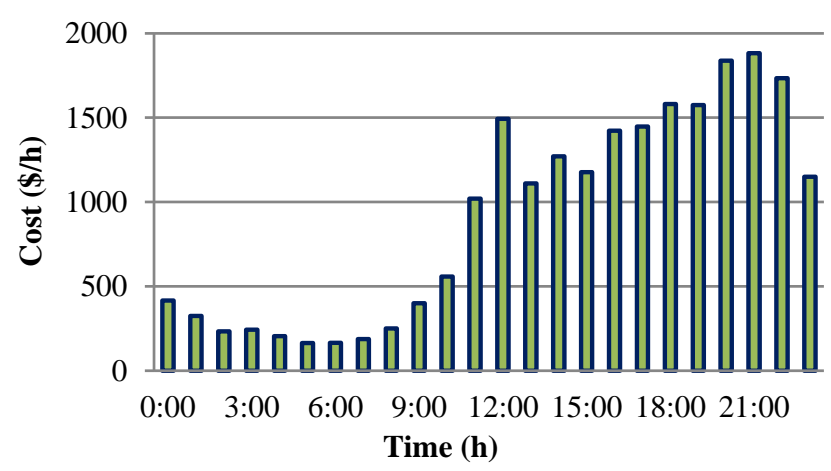

(b) 


\section{Conclusions}

A simple and efficient DSM was proposed to solve the optimal dispatch problem of a medium-voltage MG, which comprises two $11.4 \mathrm{kV}$ primary feeders with renewable and non-renewable energy DG units. Although the power levels generated by the renewable energy DG units (e.g., wind-turbine generators and photovoltaic generation systems) are inconsistent, the non-renewable energy DG units can compensate for insufficient power for load demand to maintain power balance, especially under autonomous conditions. In terms of generation, control, and MG operation, an optimal dispatch problem should be considered. Therefore, we propose an objective function that considers the minimization of fuel costs, the constraints of power generation limits, and power balance. The optimal dispatch problem was also solved by the DSM program implemented using a MATLAB R2008a software package and tested on a Windows XP-based Intel ${ }^{\circledR}$ Core $^{\mathrm{TM}} 2$ Quad CPU Q6600 @2.4 GHz processor. The generation cost of the grid-tied MG is lower than that of the autonomous MG because of the high fuel cost of DG units as evaluated against the underestimated electricity rate in Taiwan. Moreover, as the incremental cost of the DG increases, its power generation decreases after load demand increases. The proposed DSM is highly suitable for solving the optimal dispatch problem in MGs.

\section{Acknowledgments}

The author would like to thank the National Science Council of Taiwan, for the financial support under Grant No. MOST 103-2221-E-018-020.

\section{Author Contributions}

The initial idea and implementation of the proposed direct search method for optimal dispatch of DG in MG was done by Wei-Tzer Huang. Kai-Chao Yao evaluated the simulation results and corrected the manuscript. The power flow program was performed by Chun-Ching $\mathrm{Wu}$, and the simulation results were also checked by him.

\section{Conflicts of Interest}

The authors declare no conflict of interest.

\section{References}

1. Chen, A.C.M. Power/energy: Automated power distribution: Increasingly diverse and complex power operation and distribution systems will mean a larger role for microprocessor and communications technologies. IEEE Spectr. 1982, 19, 55-60.

2. IEEE Standard for Interconnecting Distributed Resources with Electric Power Systems; IEEE Std 1547-2003; The IEEE Standards Association: Piscataway, NJ, USA, 2003; pp. 1-28.

3. Measurement and Assessment of Power Quality Characteristics of Grid Connected Wind Turbines; IEC 61400-21; International Electrotechnical Commission: Geneva, Switzerland, 2001.

4. Lasseter, R.H. Smart distribution: Coupled microgrids. IEEE Power Energy Mag. 2011, 99, 1074-1082.

5. Hatziargyriou, N.; Asano, H.; Iravani, R.; Marnay, C. Microgrids. IEEE Power Energy Mag. 2007, 5, 78-94. 
6. Yu, W.; Liu, D.; Huang, Y. Operation optimization based on the power supply and storage capacity of an active distribution network. Energies 2013, 6, 6423-6438.

7. Kim, H.-M.; Lim, Y.; Kinoshita, T. An intelligent multiagent system for autonomous microgrid operation. Energies 2011, 4, 1657-1686.

8. Liu, Y.; Huang, G.; Cai, Y.; Dong, C. An inexact mix-integer two-stage linear programming model for supporting the management of a low-carbon energy system in China. Energies 2013, 6, 6045-6059.

9. Jin, H.; Xu, G.; Han, W.; Gao, L.; Li, Z. Sustainable development of energy systems for western China. Energy 2010, 35, 4313-4318.

10. Chen, C.; Duan, S.; Cai, T.; Liu, B.; Hu, G. Smart energy management system for optimal microgrid economic operation. IET Renew. Power Gener. 2011, 5, 258-267.

11. Mohamed, F.A.; Koivo, H.N. System modeling and online optimal management of MicroGrid using Mesh Adaptive Direct Search. Int. J. Electr. Power Energy Syst. 2010, 32, 398-407.

12. Chung, I.Y.; Liu, W.; Cartes, D.A.; Moon, S. Control parameter optimization for multiple distributed generators in a microgrid using particle swarm optimization. Eur. Trans. Electr. Power 2011, 21, 1200-1216.

13. Kuo, M.T.; Lu, S.D. Design and implementation of real-time intelligent control and structure based on multi-agent systems in microgrids. Energies 2013, 6, 6045-6059.

14. Hooke, R.; Jeeves, T.A. "Direct search" solution of numerical and statistical problems. J. Assoc. Comput. Mach. 1961, 8, 212-229.

15. Chedid, R.; Akiki, H.; Rahman, S. A decision support technique for the design of hybrid solar-wind power systems. IEEE Trans. Energy Convers. 1998, 13, 76-83.

16. Marwali, M.K.C.; Haili, M.; Shahidehpour, S.M.; Abdul-Rahman, K.H. Short-term generation scheduling in photovoltaic-utility grid with battery storage. IEEE Trans. Power Syst. 1998, 13, 1057-1062.

17. Misas, H. Wind Energy Potential at Yale's West Campus Using Modern Large-Scale Turbines; Yale Wind Energy Report; Yale University: New Haven, CT, USA, 2009.

18. Gavanidou, E.S.; Bakirtzis, A.G. Design of a standalone system with renewable energy sources using trade off methods. IEEE Trans. Energy Convers. 1992, 7, 42-48.

19. Lasnier, F.; Ang, T.G. Photovoltaic Engineering Handbook; IOP Publishing Ltd.: New York, NY, USA, 1990.

20. Wood, A.J.; Wollenberg, B.F. Power Generation Operation and Control; John Wiley \& Sons, Inc.: New York, NY, USA, 1996.

21. Mohamed, F.A. Microgrid Modeling and Online Management. Ph.D. Thesis, Helsinki University of Technology, Espoo, Finland, 17 January 2008.

22. Ahn, S.J.; Nam, S.R.; Choi, J.H.; Moon, S.I. Power scheduling of distributed generators for economic and stable operation of a microgrid. IEEE Trans. Smart Grid 2013, 4, 398-405.

23. Chen, T.H.; Chen, M.-S.; Hwang, K.-J.; Kotas, P.; Chebli, E.A. Distribution system power flow analysis-A rigid approach. IEEE Trans. Power Deliv. 1991, 6, 1146-1152.

(C) 2014 by the authors; licensee MDPI, Basel, Switzerland. This article is an open access article distributed under the terms and conditions of the Creative Commons Attribution license (http://creativecommons.org/licenses/by/4.0/). 